\title{
ICETE 2018
}

$15^{\text {th }}$ International Joint Conference on e-Business and Telecommunications

\section{PROCEEDINGS}

Volume 1: DCNET, ICE-B, OPTICS, SIGMAP and WINSYS

Porto, Portugal

26-28 July, 2018

EDITORS

Christian Callegari

Marten van Sinderen

Paulo Novais

Panagiotis Sarigiannidis

Sebastiano Battiato

Ángel Serrano Sánchez de León

Pascal Lorenz

Mohammad S. Obaidat

http://www.icete.org

SPONSORED BY

IIIstICc
PAPERS AVAILABLE AT

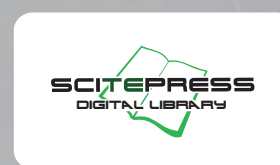




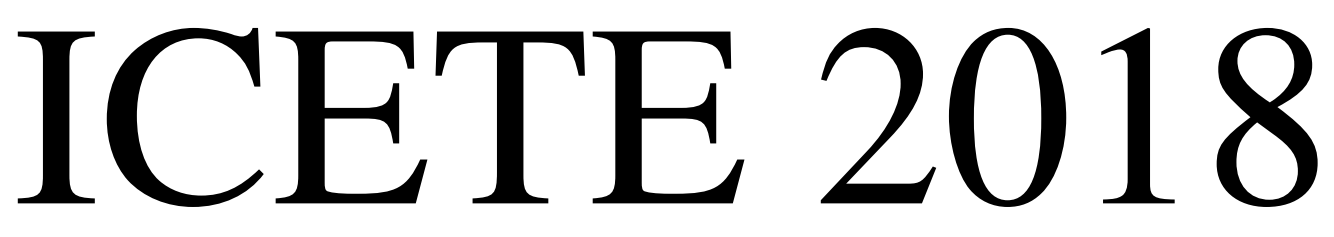

\author{
Proceedings of the \\ 15th International Joint Conference on \\ e-Business and Telecommunications
}

Volume 1: DCNET, ICE-B, OPTICS, SIGMAP and WINSYS

\author{
Porto - Portugal
}

July $26-28,2018$

Sponsored by

INSTICC - Institute for Systems and Technologies of Information, Control and Communication

Technically Co-sponsored by

IEEE Systems Council - IEEE System Council

In Cooperation with

ACM SIGMM - ACM Special Interest Group on Multimedia

ACM SIGMIS - ACM Special Interest Group on Management Information Systems

EOS - European Optical Society

Photonics21 
Copyright $\odot 2018$ by SCITEPRESS - Science and Technology Publications, Lda.

All rights reserved

Edited by Christian Callegari, Marten van Sinderen, Paulo Novais, Panagiotis Sarigiannidis, Sebastiano Battiato, Ángel Serrano Sánchez de León, Pascal Lorenz and Mohammad S. Obaidat

\section{Printed in Portugal}

ISSN: $2184-2825$

ISBN: 978-989-758-319-3

Depósito Legal: 442616/18

http://www.icete.org

icete.secretariat@insticc.org 


\title{
Smart Retail in Smart Cities: Best Practice Analysis of Local Online Platforms
}

\author{
Katrin Schade, Marcus Hübscher and Tanja Korzer \\ Institute of Urban Development and Construction Management, Leipzig University, \\ Grimmaische Straße 12, Leipzig, Germany \\ $\{$ kschade, huebscher,korzer\}@wifa.uni-leipzig.de
}

Keywords: e-Commerce, Local Online Platform, Smart City, European City, Smart Retail.

\begin{abstract}
Against the background of urban transformation processes aggravated by e-commerce, this paper discusses chances and challenges of local online platforms. Three hypotheses are introduced. Firstly, the rapid emergence of numerous local online platforms in various European countries is linked to the urban heritage of the European City. Secondly, the success of these platforms depends on the integration of diverse services. Thirdly it is argued, that platforms need to adapt to future topics of smart retail which is why a more holistic approach is appropriate. A best practice analysis is conducted, which gives an insight into the variety and complexity of local online platforms.
\end{abstract}

\section{ADAPT OR DIE: SPATIAL IMPACTS OF E-COMMERCE}

High growth rates in e-commerce have contributed to urban transformation processes in Europe in the last decade (Beckmann et al., 2016, p. 8). Location-wise, primary effects of e-commerce caused by market leaders such as Amazon and eBay are expected to change persisting structures in the retail sector. In Germany alone, a close-down of 50.000 shops is predicted until 2020 (HDE, 2016). As a consequence, shop vacancies rise and city centers decline (fig. 1).
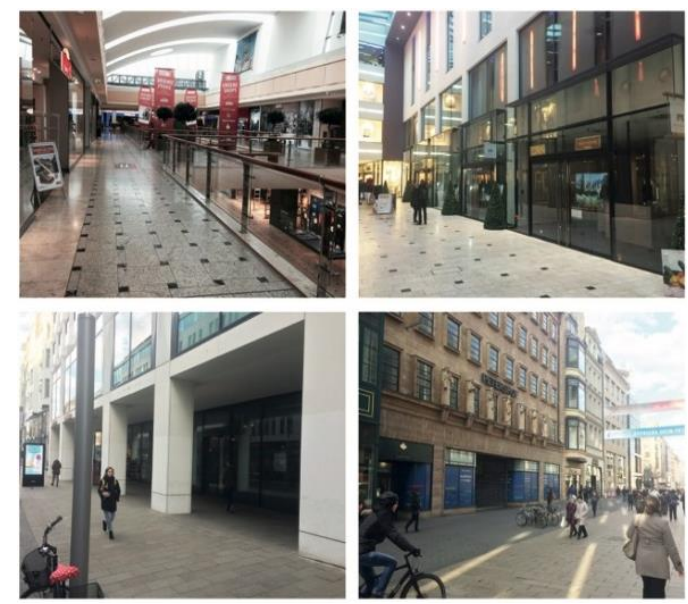

Figure 1: Shop vacancies in different (sub)urban settings in Leipzig (2018), own source.
Whereas mainly small towns used to be affected, shop vacancies in city centers in e.g. Leipzig are already noticeable. Operation-wise, especially small and medium-sized owner-managed retailers struggle to get involved with omni-channel services, whereas chain stores tend to adapt faster to trends in ecommerce.

\subsection{The Origin of Local Online Platforms}

For the last six years, diverse digital bottom-up retail initiatives in Germany and other European countries have been emerging. The main goal of these so called local online platforms (LOPs) is to retain purchasing power in the respective region, concerning only respective local, mainly brick and mortar retailers.

LOPs network local retailers with a universal digital platform, such as homepage or app. Some platforms also contain location-based information, for example event calendars or information on local activities in the city centers. Either way, LOPs present a multilateral approach by initiating omni-channel services which aim to improve retailers' perception through customers in digital and urban space, to survive on the market.

Probably one of the most popular LOPs within the academic discourse that emerged in Germany is 'Online City Wuppertal'. The platform started in 2013, funded as a pilot project of the joint initiative 
of the German state, its counties and cities, called 'Nationale Stadtentwicklungspolitik' (national urban development policy). The pilot project 'Online City Wuppertal' aims at transforming stationary retail, with the help of omni-channel services (Haderlein, 2018). The website of 'Online City Wuppertal' includes 59 different profiles of mainly local retailers who have a local store in Wuppertal. For local retailers, an advantage of the platform is that the operator helps local retailers, who do not have an own web shop, to sell their products online through the website of 'Online City Wuppertal'. The website contains a large categorized web shop out of all the products the participating local retailers offer, like a local version of Amazon. Local retailers who already have an own web shop or website can also become members. For them, the advantage is that the platform has an own budget for marketing that is larger than the expected budget of a single local retailer. Thus, 'Online City Wuppertal' contributes to improving, the local retailers' perception through customers in digital and urban space and to survive on the market. Additionally, the platform contains a few urban services, e.g. it informs about local events in the city center of Wuppertal. However, the success of 'Online City Wuppertal' seems to be unsteady for different reasons, e.g. the number of customers visiting and buying on the platform is low (Haderlein, 2018).

By now, Germany counts more LOPs than any other country. The platforms try to follow the example of 'Online City Wuppertal' or even become more successful (CIMA, 2018). However, the platforms differ from each other concerning their functionalities and specializations. There seem to be relevant differences that lead to either success or failure of LOPs which is why the paper offers a best practice analysis. The authors aim to analyze chances and challenges of LOPs to offer smart retail services in smart cities.

\subsection{Aim and Scope of the Paper}

To address the lack of research, a best practice analysis of LOPs is carried out, focusing on the chances and challenges of existing platforms. This is done in the light of smart cities. Within the analysis, the importance of a more holistic approach is demonstrated. We propose three hypotheses. Firstly, the high amount of LOPs in Europe raises the question, why similar strategies cannot be observed in comparable economic contexts such as North America. We explain this by means of a literature review of the historic development of each city model and argue that characteristics of the European City facilitate the emergence of local online platforms.

Whereas most platforms' focus lies on commerce, there are also LOPs that contain urban, especially city center-relevant services, in addition to retail services, such as 'Online City Wuppertal', e.g. they inform about local events or list local clubs. The location specific aspects help to distinguish cities and contribute to their uniqueness. Introducing the empirical analysis with the second hypothesis, we claim that the success of local online platforms depends on the integration of diverse services. The strength and competitiveness therefore lies in the location's specific characteristics.

Currently, one notices a rise and fall of LOPs. This might be due to the platforms' still being in a starting phase. Also the high number of competitors plays a key role. We thirdly argue that local online platforms need to adapt to future topics of smart retail in order to survive on the market.

\section{STATE OF THE ART IN RESEARCH}

At the present time only few scholars have examined LOPs. This sections gives an overview about the existing framework sources, starting with the concepts of smart city and smart retail. Emphasis is put on the spatial distribution of emerging LOPs. Therefore, geographical patterns are not only identified, but also tried to understand by means of the existing academic discourse.

\subsection{Future Topics of Smart Retail}

The smart city approach does not primarily refer to ecommerce. However, according to Silva et al. (2018, p. 700) "[...] utilization of best practices and applications of e-commerce and e-business to escalate the city productivity is known as smart economy. [...]". Moreover, Bakıcı et al. (2013, p. 139) define the "[...] smart city as a high-tech intensive and advanced city that connects people, information and city elements using new technologies in order to create a sustainable, greener city, competitive and innovative commerce, and an increased life quality." Silva et al.'s discussion of the smart city, is based on the city of Barcelona. Both definitions highlight a strong interaction between smart city and e-commerce. This interaction is taken into consideration when future topics of smart retail are defined and analyzed. The following future topics 
of smart retail are examined within SURTRADE (2018), a current research project in Germany that focuses on smart urban retail services. The future topics will be applied later in this paper, in order to explain the possible survival of LOPs on the market: Integration, Usability, Community and Sustainability.

Integration describes e-commerce interfaces including different urban functions. Smart cities represent diverse urban functions in their centers apart from commerce such as gastronomy, different kinds of services, tourist attraction activities and others. Hence, looking at LOPs an integrated approach needs to be adapted in order to show smart cities' diversity.

Usability refers to the design and accessibility of digital services, which are going to be more individual in smart cities and particularly ecommerce in the future. All services should be accessible to everyone in every location.

The third overlapping future topic is Community. It refers to the fact that multidimensional communication and networking in smart cities as well as e-commerce is becoming more and more important. Concepts of Community such as sharing and the networking of interest groups need to be simplified.

Fourthly, Sustainability is an overall relevant aspect in smart cities and e-commerce concepts. One can differ between financial, ecological and social Sustainability (Adams 2006). When it comes to stamina of e-commerce platforms, primarily financial Sustainability must be regarded. Especially when brick and mortar retail is already struggling, a sustainable financing concept for the applying ecommerce platform is an important issue. However, e-commerce is not just a temporal phenomenon and needs to be strongly adapted to brick and mortar retail in future smart cities.

\subsection{Mapping LOPs}

LOPs are a relatively new phenomenon. Data, both on concept and economic success is rare (Beckmann et al., 2016: 10). However, a few primary studies exist whose results are available online. In 2015, the company CIMA Beratung + Management GmbH was commissioned by the Bavarian Ministry of Economic Affairs and Media, Energy and Technology and the Bavarian Trade Association to investigate LOPs. Due to the rapid development in the area, the project stakeholders decided to expand the market investigation. Data is available on the website 'Gemeinsam Online' (English: together online). The high and continually increasing amount of platforms on the website provides a comprehensive overview of platforms in Germany. The study, however, does not consider LOPs outside of the country. In contrast to this, the website 'Local Commerce' offers an insight into platforms in Europe and is updated regularly by its initiator Andreas Haderlein. The website lists related local stakeholders and provides an overview on the strengths and weaknesses of each platform in relation to their relevance for e-commerce. Despite both investigations' relevance for local e-commerce, no comparative research of LOPs has been done so far. Analyzing existing framework sources from a spatial point of view, the vast majority of LOPs can be found in European cities, with highest densities in Germany, Switzerland, Austria and Italy. Only a small fraction of platforms is detected outside of Europe, such as Shop Midland, Canada. Thus, the distribution of LOPs seems to follow a certain spatial pattern and needs to be questioned.

\subsection{The European City - Cradle of Local Online Platforms?}

LOPs emerge in several European cities. In no other part of the world, a similar density of platforms can be observed so far. Surprisingly, the United States of America show a much higher level of digitalization than the European Union, when it comes to businesses and economics (McKinsey and Company, 2016, p. 12). Consequently, there must be another explanation for the high number of already existing LOPs in Europe. This section develops the hypothesis that the emergence of digital bottom-up retail initiatives is strongly linked to the traditions of the European City, as an antithesis to American urbanism.

One of the main reasons that has probably caused the rise of LOPs is the aim to compensate loss in total revenue of brick and mortar retail. Particularly small and medium-sized towns are predicted to be the losers of retail digitization (BearingPoint und IIHD, 2015, p. 8). In spite of that, the example of Leipzig shows, that vacancies are an issue even in Germany's fastest growing city (Leibert, 2017, p. 10), counting about 600.000 inhabitants and approx. increasing by 20.000 people per year. Over the last ten years, vacancy rates in Leipzig's city center oscillated between nine and twelve percent (Korzer et al., 2017, p. 3). In different urban settings persistent vacancies can be observed, such as in greenfield shopping malls, secondary prime locations or even high streets.

These trends apply to cities worldwide, such as in Akure, Nigeria (Bello and Ezeokoli, 2015); the UK 
(Hughes and Jackson, 2015) or the U.S. (Bushmeneva 2016), but the reactions differ particularly between American and European cities. Based on theory in urban geography, the following paragraphs outline both city models, highlighting aspects that influence the rise of LOPs.

The model of the American City has been depicted by Burgess in the 1920s. His concentric zone model characterizes the Central Business District (CBD) as the center of economic, cultural and political life (Jessen, 2002, p. 212). Häußermann points out that CBDs have been mainly characterized by commercial usages before WW2, which means that a change of center-specific functions has taken place since then (Häußermann, 2001, p. 249). Particularly the process of suburbanization has undermined existing functional structures in the city. Based on increasing real incomes, a vast part of the society was able to realize their American dream of living in single-family homes in the suburbs (Hahn, 2014 , p. 20). The residential suburbanization was followed by a commercial suburbanization from the 1950s onwards (Jessen, 2002, p. 214), reinforcing the competition between center and greenfield. Moreover, the development of shopping malls, based on the ideas of Victor Gruen, has been transforming periphery-center relations since then (Hahn 2014, p. 109; see alsp Fig. 5). Thus, the degradation of city centers in the American City is not a new phenomenon but has been evolving since the early 1940s (Hahn, 2014, p. 74). In that respect, digitization can be regarded as a process reinforcing the competition between center and suburb.

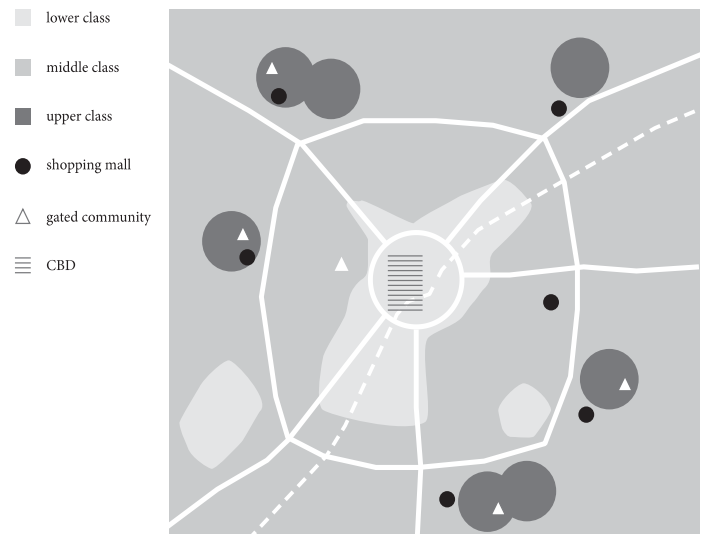

Figure 2: American urbanism between CBD and suburbs, based on Michael (2015, p. 222).

To some extent, this also applies to European cities. However, the original conditions are different there. In the European City, history and tradition play a crucial role. The city center was and still is a place of identification (Häußermann, 2001, p. 249). It connects different functions such as living, commerce, labor, culture and education in the same public space (Hassenpflug, 2002, p. 43). Compared to North America, commercial suburbanization hit European countries not only later, their locations were also much more controlled by planning authorities (Klus 2013, pp. 20-21). Consequently, the city center has been able to keep much of its commercial function until now (Jessen, 2002, p. 220). Nevertheless, e-commerce poses a new and additional challenge for brick and mortar retailers leading to decreasing sales and close-down of shops. Thus, digitization in the European context coincides with more or less intact retail structures in city centers compared to American cities. Consequently, the emergence of LOPs can be regarded as a response to these negative outcomes from the retailer's point of view. However, these platforms should not be regarded as protest. They rather try to cope with digitization in a proactive way. Apart from that, the rise of these platforms can also be traced back to a broad civic consciousness in the European City. Most of the analyzed platforms have been initiated by means of digital bottom-up retail initiatives, e.g. by citizens, local retailers or local IT companies. Moreover, there is a tradition of sovereign intervention when it comes to urban planning and social balance in the European City (Jessen, 2002, p. 218-219). In the case of LOPs, public subsidies and a strong cooperation with authorities play a crucial role, always trying to balance free market economy and preservation of European urban identities.

In summary, the aspects mentioned above facilitate the emergence of LOPs in European cities. Of course, models such as the European or American City are theoretical constructs (Böhme, 2002, p. 49). In spite of that, several common and opposite aspects cannot be denied in both cultural areas. In a globalizing world, the differences between both city models seem to blur. Aspects of the American urbanism have been taken over in Europe in the last decades, such as shopping architecture or marketorientation of administration. Simultaneously in North America, city planners have proclaimed the European model as a possible answer to the urban problems there (Jessen, 2002, p. 223). Against the background of Sustainability objectives, the European City serves as a model for urban planning and design (Hannemann and Mettenberger, 2011, p. 68). Digitization poses challenges to both continents and requires smart answers. 


\section{METHOD}

\subsection{Method and Background}

With the thought of LOPs still being a phenomenon of the European City but drawing a potential for other city models such as the American City, it is still uncertain, how platforms differ from each other and what kind of functionalities help LOPs to survive on the market. A best practice analysis of LOPs shall help to analyze chances and challenges of the platforms in the light of smart cities. The best practice analysis of existing platforms is based on a quantitative analysis (fig. 3).

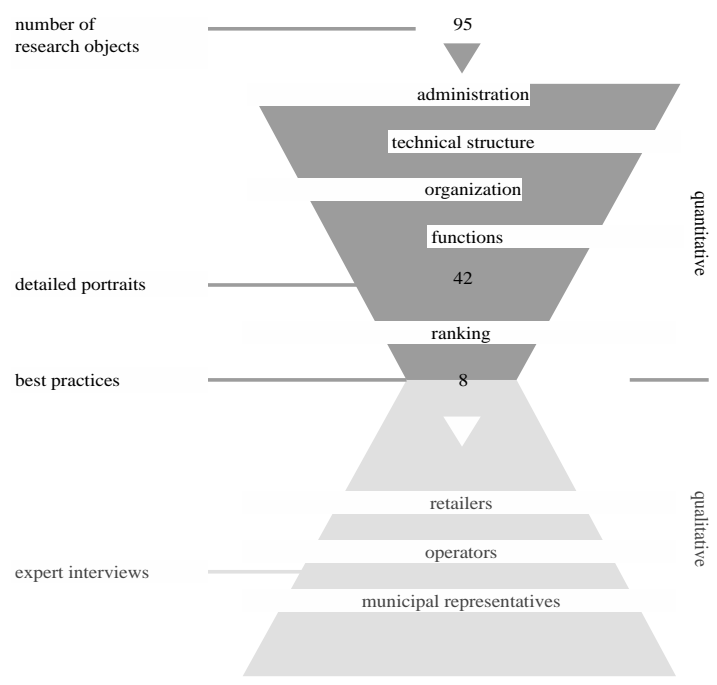

Figure 3: Best practice analysis of LOPs, own source.

The analysis of LOPs will be completed by a qualitative analysis, in order to get specific information concerning chances and challenges of best practice LOPs. The paper at hand concentrates on findings of the quantitative analysis.

The first step of the best practice analysis is to detect LOPs. We find evidence on different websites (fig. 4).

LOPs are also detected by searching online with key words in order to look for incidences worldwide. This happens to be rather complicated because of difficulties to find the right keywords. Since LOPs are a new phenomenon, there are different expressions for the same meaning. For example, in German one can refer to "Lokale Online-Plattformen" (English: Local Online Platforms) in the same way as "Lokale Online-Marktplätze” (English: Virtual Local Marketplaces). Also word combinations like "brick and mortar retail online", "municipal center AND virtual AND marketplace", "together online AND commerce" or "smart retail service platform" are used and translated into other languages.

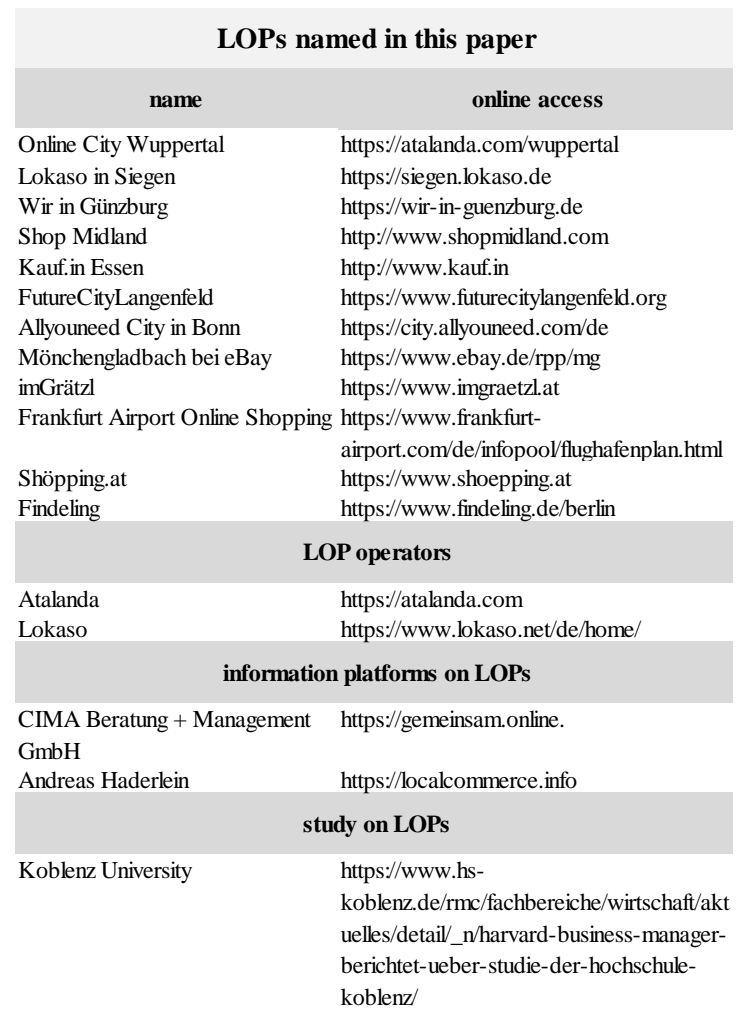

Figure 4: LOPs named in this paper, own source.

\begin{tabular}{ll} 
best practice LOPs & $\begin{array}{l}\mathbf{x} \text { out of } \mathbf{1 2} \text { functionalities offered + } \\
\text { specialization }\end{array}$ \\
\hline Online City Wuppertal & 8 (spec.: most functionalities) \\
Lokaso in Siegen & 8 (spec.: logistic services) \\
imGrätzl (Vienna) & 7 (spec.: city districts) \\
Wir-in-Günzburg.de & 6 (spec.: online advertising \& communication) \\
shöpping.at & 5 (spec.: platform of platforms) \\
Findeling & 5 (spec.: selected vendors) \\
Frankfurt Airport Online Shopping & 5 (spec.: certain space) \\
Future City Langenfeld & 1 (spec.: concept of urban development)
\end{tabular}

Figure 5: eight best practice LOPs concerning functionalities, tools \& services and specialization, based on Haderlein.

We find 95 different LOPs and identify 42 out of 95 platforms that stand out due to their number of functionalities, tools and services (Haderlein 2018). Fig. 5 displays the different functionalities and, as an example, the the tools and services of the functionality 'cross-channel services'. The selection is done by a tabular display of the LOPs with the counted numbers of functionalities, tools and services per LOP.

We then rank the platforms and filter eight best practices concerning their amount of functionalities, tools and services but also their different 
specializations (fig. 6). We then focus on future topics of smart retail in order to show how LOPs apply to them, which is explained under 3.2.

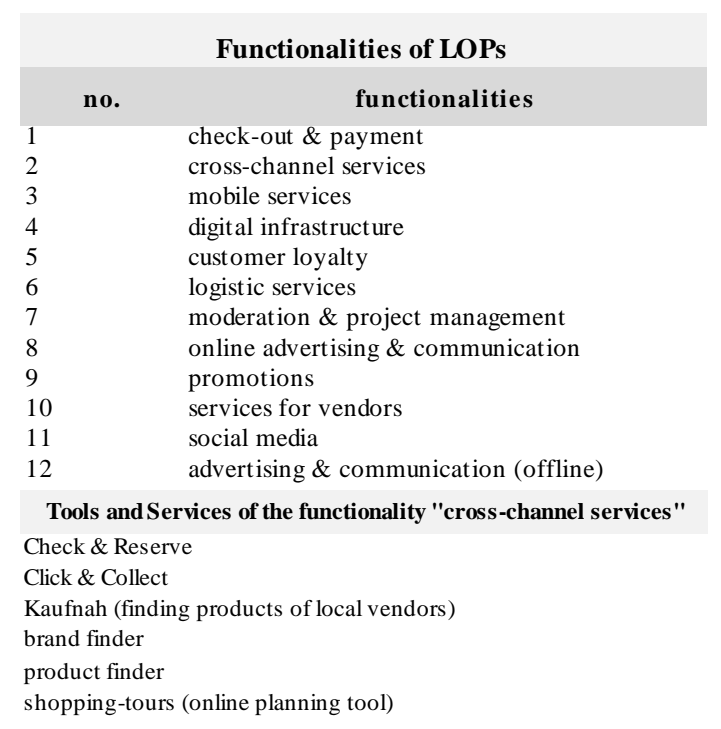

Figure 6: functionalities and tools \& services of LOPs, based on Haderlein.

\subsection{Measuring Future Topics in LOPs}

\begin{tabular}{ll} 
Integration & $\begin{array}{l}\text { urban functions, for example notification of } \\
\text { events in the city, information apart from local } \\
\text { retail in the respective region } \\
\text { measurement: available / partially av. / not av. }\end{array}$ \\
Usability & $\begin{array}{l}\text { open accessibility, digital services in the form of } \\
\text { categorization of products and stakeholders, } \\
\text { compatibility with different digital devices } \\
\text { (mobile, laptop, computer) }\end{array}$ \\
& $\begin{array}{l}\text { measurement: open accessibility: yes / no; } \\
\text { digital services: available /partially av. / not av.; } \\
\text { compatibility: all / two / not }\end{array}$ \\
Community & $\begin{array}{l}\text { sharing concepts, B2B+B2C+C2C communication, } \\
\text { number and activity of platform stakeholders } \\
\text { measurement: sharing: yes / partially / no; } \\
\text { B2B+B2C+C2C: all / two / one / no; number of } \\
\text { stakeholders: more than 3 / 2-3 / 1; activity of } \\
\text { stakeholders: all / more dimensional / one dim. }\end{array}$ \\
Sustainability & $\begin{array}{l}\text { social, ecological, financialeconomical } \\
\text { measurement: available / partially av. / not av. }\end{array}$ \\
\hline
\end{tabular}

Figure 7: Characteristics of future topics and way of measurement in the best practice analysis, own source.

Concerning the smart city approach, future topics of smart retail investigated by the research project SURTRADE (2018) were named in section 2.1. Fig. 7 summarizes the characteristics of each future topic.
In the quantitative analysis we use the future topics to explain chances and challenges of LOPs in relation to smart retail services. Therefore, fig. 7 also contains a measurement to what extent the future topics are considered by the eight best practice LOPs.

\section{ANALYSIS OF LOCAL ONLINE PLATFORMS}

Based on the method described in the section before this chapter presents the empirical findings. Firstly, the structural similarities and differences of selected 42 LOPs are outlined. Secondly, the eight best practice LOPs will be measured concerning future topics of smart retail.

\subsection{More than Shopping?}

In the paper, it was argued that the emergence of LOPs is strongly linked to the characteristics of the European City. Apart from this spatial perspective, platforms' specialization in the light of functionalities and services are also a relevant aspect. The platforms started to emerge in 2011 (fig. 8). Particularly from 2012 on, a rising growth rate in total start-ups can be observed each year, peaking in 2015. After that, the growth rate slowed down again. In addition, a constant number of close-downs can be observed from 2015 on.

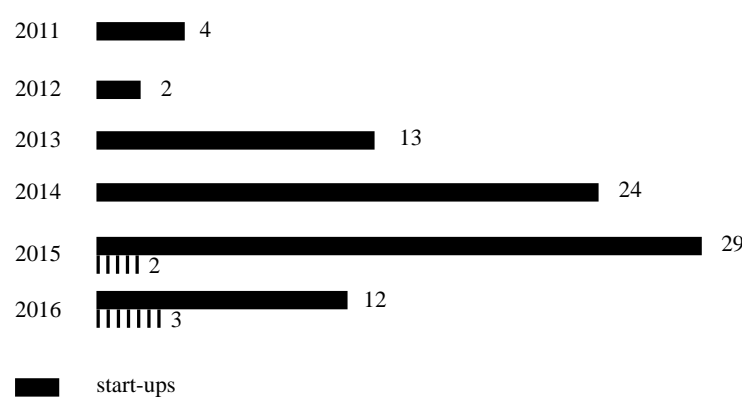

Figure 8: Start-up of online-platforms, based on Haderlein (2018).

There is a possible relation between start-ups and the product lifecycle model of Vernon (1966, p. 16). The model identifies five stages of product development: introduction or launching phase, growth, maturity, saturation and decline. During the first phase of introduction, a high number of products from different companies emerges. For reasons of competitiveness, not all products persist on the market. When it comes to LOPs, a similar conclusion 
can be drawn. Of course, these platforms do not compete with each other directly due to their locationbased approach. Still, without public funding, platforms need to perform in a financially sustainable way in order to survive on the market. Difficulties might arise due to a lack of professionalism, acceptance or integration. Considering LOPs as products in a lifecycle, it can be pointed out that their launching phase is still ongoing. In this stage of trial and error, a strong market movement is still to be expected. In spite of that, several companies started exporting their business models to various cities, namely Atalanda and Lokaso competing for leadership on the German market.

Apart from the numeric monitoring of the platforms, structural similarities and differences were analyzed beneath 42 profiled LOPs. Firstly, in most of the platforms, communication takes place in a onedimensional meaning, i.e. vendors utilize platforms by providing information to the customer. Contrary to that, a mutual exchange between retailers and customers or a link between customers does rarely take place. In Kauf.in Essen for example, this is exactly the case. Although the platform focuses on promoting products no communication between involved players takes place which can be considered as one of the reasons for its current closure.

Secondly, few platforms integrate urban functions apart from commerce. Of course, retail is one of the main motivations for LOPs to emerge. However, the success of these platforms also depends on the overall attractiveness for their users, which might increase by providing different services. While Lokaso in Siegen currently shows growing sales without integrating functions apart from commerce, other platforms such as FutureCityLangenfeld try to draw a complete digital image of the urban.

Thirdly, platforms tend to specialize in one function, which is considered as a strategy to develop and apply expert knowledge and to offer professional services. The example Allyouneed City in Bonn specializes in logistics, providing highly sophisticated services, for example a delivery-time within 120-minutes.

Fourthly, in most of the platforms a lack of active participation of local stakeholders can be identified. However, this is crucial for a platform that needs to develop persistent structures. Networks and integration contribute to the acceptance of platforms, in addition to stationary shopping. Only multiple stakeholders are able to represent the plurality of the urban. Mönchengladbach bei eBay, a local platform using eBay's infrastructure, may enjoy high popularity due to its brand, but it fails to connect urban stakeholders.

LOPs are still in the phase of introduction. Their success is difficult to measure solely from an ex-post perspective. Considering the constraints of such analysis, a representative survey conducted by Koblenz University revealed that platforms did not significantly increase sales for most of the 200 interviewed retailers. This illustrates the difficulties that these platforms face, especially in their initial phase (Reimann 2018, n.p.). In order to work successfully, platforms have to be designed in a financially sustainable way, provoking daily visits of their customers and addressing different target groups.

\subsection{Smart Retail in Smart Cities}

In section 2.1, Integration, Usability, Community and Sustainability were defined as future topics of smart retail. In order to find out about LOPs chances and challenges to survive on the market, the eight best practice LOPs are measured concerning their consideration of the future topics in this section. Of particular interest are similarities and differences of LOPs, specific examples will be given.

Integration of LOPs can be divided into two categories. First, platforms were viewed with regard to their inclusion of diverse stakeholders. Second, functionalities and services that went beyond commerce in the light of other city-center relevant functionalities, were identified. It is noticeable that the platforms differ to a great extent in the involvement of number and type of stakeholders. Commonly, they involve local stakeholders to guarantee the projects' funding on the one hand, and possibly, to build credibility among interest groups, on the other hand. Frequently, projects are financed from different sources. It is not uncommon for the federal state, the city and the operator to pay costs that can only be partially transferred to the participating vendors. Even though local stakeholders are involved in financing the project, it is not clear to what extent they are in fact actively involved in the project's content. They might merely be advocates or donors or both. Typically, local stakeholders are respective states, city administrations, chambers of industry and commerce, city marketing associations, private associations, restaurateurs, banks and other service providers, for example in the field of logistics and others. Some platforms are even involved in regional initiatives such as marketing campaigns like 'buy local' or 'Heimat shoppen' (English: home town shopping), in which respective stakeholders often 
firstly get to know each other. However, from the quantitative results, initially no conclusions can be drawn from the amount of stakeholders on the success of the respective platforms because this would require a network analysis. Considering that, the Integration of other city-center relevant functionalities beyond commerce are regarded and differences are determined. Most platforms focus solely on commerce associated with optimizing omni-channel services. There are a few platforms, such as Wir in Günzburg, which illustrate a local event calendar, gastronomy and an overview of private associations on site. Also, there are few examples such as imGrätzl from Vienna in Austria, which do not consider commerce as being independent. The operator understands commerce in a neighborhood-based approach which is similar to the functional, multifaceted structure of a neighborhood, without focusing on commerce itself.

Usability can be divided into three categories. First of all, it is important to which extent respective platforms are compatible to different target and interest groups. In this regard, it is interesting, whether people are capable and therefore willing to use the platform. This can, for example, depend on quantitative factors such as age, gender, family situation, work, education, but also habits, disabilities or specific everyday situations. Secondly, Usability is determined by the website design, i.e. clarity, help and contact details, comprehensiveness of product categories, search settings and other special features. Thirdly, the compatibility of various devices is essential for the shopping experience. Overall, most LOPs are well structured. Frequently, shopping is divided into categories such as fashion, electronics or books, each of which can be subdivided. Most platforms proof to be clear and relatively easy to use. There is a lack of detailed product descriptions, so that the desired product is sometimes assigned to a wrong category or to not only one but several matching categories. Here, an improvement must be achieved in the future. Differences were investigated in terms of website presentation. The arrangement of individual search areas or applications are only partly well-placed. As a result, the time required to navigate the respective platforms increases and reduces the chance of re-use at the same time. A particularly creative website presentation can be achieved for example via so-called "gamification". This term is defined as "a process of enhancing a service with affordances for gameful experiences in order to support user's overall value creation." (Huotari and Hamari 2012, p. 19). Non-local retail platforms such as Mister Spex (https://www.misterspex.de) already apply this. The exclusive online retailer gives the user the opportunity to try on different glasses with the help of the camera of one's electronic device. Most platforms still have to catch up when it comes to gamification, in order to be competitive. Only 'Frankfurt Airport Online Shopping' uses a map of the airport area. The visitor receives information about all kinds of interesting airport services besides shopping, by clicking on different fields in the map. The website could still improve introducing more gamification elements. Not all LOPs are optimized for mobile devices, like smartphone, pad or computer. Hardly any platform has developed other applications such as apps, which might have a marketing effect and would contribute to cross-channel measures. Most platforms have help and contact options, some even have chatbots. Lokaso in Siegen integrates a personalized assistance called 'die gute Fee' (English: the good fairy). Most platforms show similar features regarding Usability but few special features could be found. There is, for example, the shipping calendar on shöpping.at, which allows customers to determine the time of the goods' delivery. In general, the more individual a page is designed, the more likely the platform will be re-used.

While some processes become more individualized, there are also future topics dealing with processes that encourage Community participation. From an operator's perspective, business to consumer communication is important (B2C). This entails that the company, be it in the form of the platform operator or in the form of the vendor, can get into contact with the consumer in order to initiate or improve processes. An example is the use of chatbots, which encourage the customer to communicate with the operator. Another example is the connection of platforms to social media. Vendors put information online for the consumer. The social media website Pinterest stands, among other things, for B2C communication. A local online platform, that uses Pinterest, serves to enable the customer to select the vendor community that he wants to follow. The platform Findeling can be mentioned here. LOPs also encourage business to business communication (B2B). This includes, in particular, the provision of vendor training, for example on how to use omnichannel features, which are carried out by the platform operators and are offered on many LOPs. So far, there are hardly any platforms with the possibility to connect customers $(\mathrm{C} 2 \mathrm{C})$. An exception is the LOP imGrätzl. On this platform, vendors, residents and other stakeholders connect with each other in the community hub. They can share ideas through various channels, including newsletters, Facebook 
and blogs. Also, imGrätzl is probably the only platform that enables sharing. Other platforms are geared to the revenue of the participating merchants and do not work in this regard. However, multidimensional communication can have a positive effect on the multiple use of the platform. For example, the large-scale omni-channel company Tchibo (https://www.tchibo-share.de) is already trying to tie customers by renting children's clothing. This effect of sharing is considered as a separate future topic here, under the term Sustainability.

In terms of Sustainability, a distinction can be made between financial, ecological and social aspects, whereby the three forms often overlap (Adams, 2006, p. 2). As mentioned before, Tchibo is testing a sharing concept on its website. The renting of children's clothing has a social and a financial as well as an ecological aspect. While parents can buy used clothes, they save money and contribute to the decrease of producing new energy-consuming goods at the same time. Also some of the LOPs pursue social Sustainability. In Siegen, for example, Lokaso is supporting a project called "Zeitungspaten für Schüler" (English: Newspaper Sponsors for Students), whereby students in Siegen can receive daily newspapers free of charge. Further fundraising events can be found on a few other platforms. The topic of ecologically sustainable delivery services is often discussed and implemented, which concerns both the consumption of materials and the delivery of goods. This is still a relatively new territory for LOPs but some have already started to use cargo bikes or ecars, for example. Another interesting project is "Raumteiler" (English: room divider) at imGrätzl, which can be understood as a cooperation with a property developer to revitalize vacant spaces in the city districts. So far, this contribution to sustainable urban development is unique among LOPs. Concerning Sustainability, the platforms still have to catch up. Especially the issue of $\mathrm{CO} 2$-free and resource-conserving delivery should be put on the agenda more strongly to further support smart retail in the future.

The analysis of eight best practices based on the future topics of smart retail describe LOPs' status quo and their chances to survive on the market. Since LOPs are still in the launching phase, further development remains to be awaited and should be analyzed.

\section{CONCLUSION: HOLISTIC APPROACH AS A FACTOR OF SUCCESS}

In this paper, three hypotheses concerning a quantitative competitor analysis of LOPs are introduced. Therefore, future topics of smart retail were defined, linking e-commerce and the smart city approach. Within the first steps of the analysis it is shown that the search of platforms by definition is difficult and requires further research. Still, 95 LOPs are found and spatial disparities among those are identified which leads to the hypothesis that the development of LOPs is strongly linked to the characteristics of the European City. Further research has to address reasons for availability or lack of platforms within various European countries and also on- and offline spaces within respective regions. Beside commerce, other center-relevant functions are identified as possible success factors of 42 profiled LOPs, which is expressed in the second hypothesis. Few LOPs tend to integrate other functions, which might be the result of the fact that platforms are in a launching phase, i.e. means they are still developing. In the third hypothesis, future topics of smart retail are applied to eight best practices of LOPs. Large gaps of development and crucial differences were identified among integrated Community features and ecological Sustainability, especially when it comes to goods delivery. Similarities were mostly striking in terms of Usability concerning platform design and clarity, even though background product descriptions ought to improve. Overall, the research refers to a more holistic approach of LOPs which also takes into account logistics, IT, urban development and business, since smart retail covers several aspects. Based on the analysis conducted, a set of factors of success can be identified (fig. 9).

\section{factors of success}

\footnotetext{
- Platforms are networks. Bottom-up projects are more likely to be successful than top-down initiatives.

- In order to address diverse target groups, platforms should integrate urban functions.

- Communication needs to be multidimensional to enable networking.

- In structurally weak regions, public funding is particularly necessary.

- Public funding helps, but a stable financial model is indispensable.
}

Figure 9: Factors of success of local online platforms, own source. 
The quantitative research approach that has been chosen for this study offered a comprehensive overview on existing platforms. In that respect, literature reviews and desktop research were the main instruments. According to their methodological constraints, no in-depth portraying was possible. In order to gain knowledge about structures and organization of platforms, a qualitative analysis has to be done. Moreover, the competitor analysis carried out so far needs to be considered as a snap-shot, observing a certain status quo. This neglects the fact that the market for LOPs is currently moving at a vast pace. The results also show the requirement to redefine the scientific understanding of platforms, since the growing variety leads to blurred definitions.

This paper argues, that the emergence of LOPs is strongly intertwined with the European City. However, further analysis needs to be done in order to understand prevailing spatial disparities. A contrast cannot only be identified between Europe and North America. Platforms currently emerge particularly in Central Europe, e.g. in Germany, Austria and Switzerland, but also in Italy, which leads to the question why these countries are currently the leaders on the market. Apart from that, even within these countries stark spatial contrasts can be observed when it comes to the distribution of platforms, opening up areas for further research.

Considered as a field of research, LOPs are relevant from different disciplines' perspectives. Of course, commerce and business belong to the most relevant aspects. Due to its smart approach, IT is a further central aspect, providing necessary infrastructures. As platforms redefine local organizations between producer, retailer and consumer, logistics is another discipline of importance. Last but not least, the research object addressed in this paper impacts spatial reorganization, requiring an urban geography approach for a better understanding of LOPs.

It remains uncertain whether LOPs as possible preforms of smart retail service platforms will prove to be viable in the future. The development and feasibility must be examined individually for each location, as this may be the real strength of urban retail locations in the future.

\section{ACKNOWLEDGEMENTS}

This research and development project is funded by the German Federal Ministry of Education and Research (BMBF) within the program "Innovations for Tomorrow's Production, Services, and Work" and managed by the Project Management Agency Karlsruhe (PTKA). The authors are responsible for the contents of this publication.

\section{REFERENCES}

Adams, Bill (2006): The Future of Sustainability. Rethinking Environment and Development in the Twentyfirst Century. Report of the IUCN Thinkers Meeting, 29-31 January 2006. https://cmsdata.iucn.org/ downloads/iucn_future_of_sustanability.pdf (24.05.2018).

Bakıcı, Tuba; Almirall, Esteve; Wareham, Jonathan (2013): A Smart City Initiative: The Case of Barcelona. In: Journal of the Knowledge Economy 4, Springer Science+Business Media. pp. 135-148.

BearingPoint; IIHD (2015): Strukturwandel im deutschen Einzelhandel. Warum gerade Klein- und Mittelstädte von den Folgen des Strukturwandels besonders betroffen sind. In: Red Paper $\mid$ Retail \& Consumer, 8. https://www.bdu.de/media/32083/manke-studie-8.pdf (02.02.2018).

Beckmann, Ralf; Hangebruch, Nina (2016): Lokale OnlineMarktplätze: ein Ansatz zur Vernetzung von Fußgängerzone und Internet. In. Stadtentwicklung. Zur Vernetzung von Fußgängerzone und Internet. In: vhw Bundesverband für Wohnen und Stadtentwicklung e.V. [eds]: Stadtentwicklung, 1, pp.7-12.

Bello, Victoria; Ezeokoli, Nnaemeka Bethel. (2015): Effect of Vacancy on Shopping Centres' Investment Returns in Akure, Nigeria. In: Ethipoian Journal of Environmental Studies \& Mangament, 8 (1), pp. 28-38.

Bushmeneva, Ksenia (2016): U.S. e-commerce disrupts traditional retail, but brings opportunities elsewhere. In: $T D$ Economics, Special Report. https://www.td.com/ document/PDF/economics/special/Ecommerce2016.pd f (14.03.2018).

Böhme, Helmut (2002): Thesen zur "europäischen Stadt" aus historischer Sicht. In: Dieter Hassenpflug [eds]: Die europäische Stadt. Mythos und Wirklichkeit. Hamburg: https://www.bdu.de/media/32083/mankestudie-8.pdf (02.02.2018)

CIMA (2018): Gemeinsam online. Untersuchung von Online-Plattformen mit lokalem Fokus https://gemeinsam.online/ (09.03.2018)

Michael, Thomas (2015): USA - Nordamerikanische Stadt. In: Diercke [eds]: Weltatlas. p. 222. Braunschweig.

HDE (2016): Pressemitteilungen 2016: Handel und Kommunen bilden Innenstadt-Allianz - Verödung der Innenstädte stoppen: https://www.einzelhandel.de/ index.php?option $=$ com_content $\&$ view $=$ article $\&$ id $=90$ 03 (05.02.2018).

Haderlein, Andreas (2018): Digitale (City-)Initiativen im Überblick. https://localcommerce.info/ (09.03.2018).

Hahn, Barbara (2014): Die US-amerikanische Stadt im Wandel. Springer, Berlin, Heidelberg.

Hannemann, Christine; Mettenberger, Tobias (2011): "Amerika" als Spiegelbild - Zur Funktion eines 
Kontrastes im Diskurs "europäische Stadt". In: Oliver Frey und Florian Koch [eds]: Die Zukunft der Europäischen Stadt. Stadtpolitik, Stadtplanung und Stadtgesellschaft im Wandel. VS Verlag für Sozialwissenschaften / Springer Fachmedien, Wiesbaden.

Hassenpflug, Dieter (2002): Die europäische Stadt als Erinnerung, Leitbild und Fiktion. In: Hassenpflug, Dieter (eds): Die europäische Stadt. Mythos und Wirklichkeit. Hamburg. pp. 11-48.

Hughes, Cathy; Jackson, Cath (2015): Death of the high street: identification, prevention, reinvention. In: Regional Studies, Regional Science, 2 (1), pp. 237-256.

Huotari, Kai; Hamari, Juhu (2012): Defining Gamification - A Service Marketing Perspective. In: Proceeding of the 16th International Academic MindTrek Conference, Tampere, Finland. ACM: New York.

Häußermann, Hartmut (2001): Die europäische Stadt. In: Leviathan 29 (2), pp. 237-255.

Jessen, Johann (2002): Amerikanische Stadt - Europäische Stadt. In: Dieter Hassenpflug (eds): Die europäische Stadt. Mythos und Wirklichkeit. Hamburg, pp.205-224.

Klus, Sebastian (2013): Die europäische Stadt unter Privatisierungsdruck. Konflikte um den Verkauf kommunaler Wohnungsbestände in Freiburg. $P h D$ thesis, Springer VS, Humboldt University, Berlin.

Korzer, Tanja; Müller, Marit; Neider, Sebastian; Weidner, Silke; Komm, Steffanie (2017): Großprojekte und Innerstädtischer Einzelhandel. Datenband $\mathrm{zu}$ einer Langzeitstudie zur Leipziger Innenstadt. Books on Demand.

Leibert, Tim (2017): Expertenwissen für Bevölkerungsvorausberechnungen - das Beispiel Leipzig. In: Stadtforschung und Statistik, 30 (2), pp. 10-14.

McKinsey \& Company (2016): Digital Europe: Pushing the Frontier, Capturing Benefits. https://www.mckinsey. com/ /media/McKinsey/Business\%20Functions/McKi nsey\%20Digital/Our\%20Insights/Digital\%20Europe\% 20Pushing $\% 20$ the $\% 20$ frontier $\% 20$ capturing $\% 20$ the $\%$ 20benefits/Digital-Europe-Full-report-June-2016.ashx (02.02.2018).

Reimann, Erich (2018): Studie: Online-Marktplätze lokaler Händler sind unzureichend. In: Heise Online, https://www.heise.de/newsticker/meldung/Studie-Onli ne-Marktplaetze-lokaler-Haendler-sind-unzureichend3959195.html (13.03.2018).

Silva, Bhagya Nathali; Khan, Murad; Han, Kijun (2018): Towards sustainable smart cities: A review of trends, architectures, components, and open challenges in smart cities. In: Sustainable Cities and Society, 38, pp. 697-713.

SURTRADE (2018): Smart Urban Retail Services. https://surtrade.org/ (25.05.2018)

Vernon, Raymond (1966): International investment and international trade in the product cycle. In: The International Executive, 8 (4), pp. 16-16. 
Proceedings of ICETE 2018 - Volume 1: DCNET, ICE-B, OPTICS, SIGMAP and WINSYS

$15^{\text {th }}$ International Joint Conference on e-Business and Telecommunications

http://www.icete.org

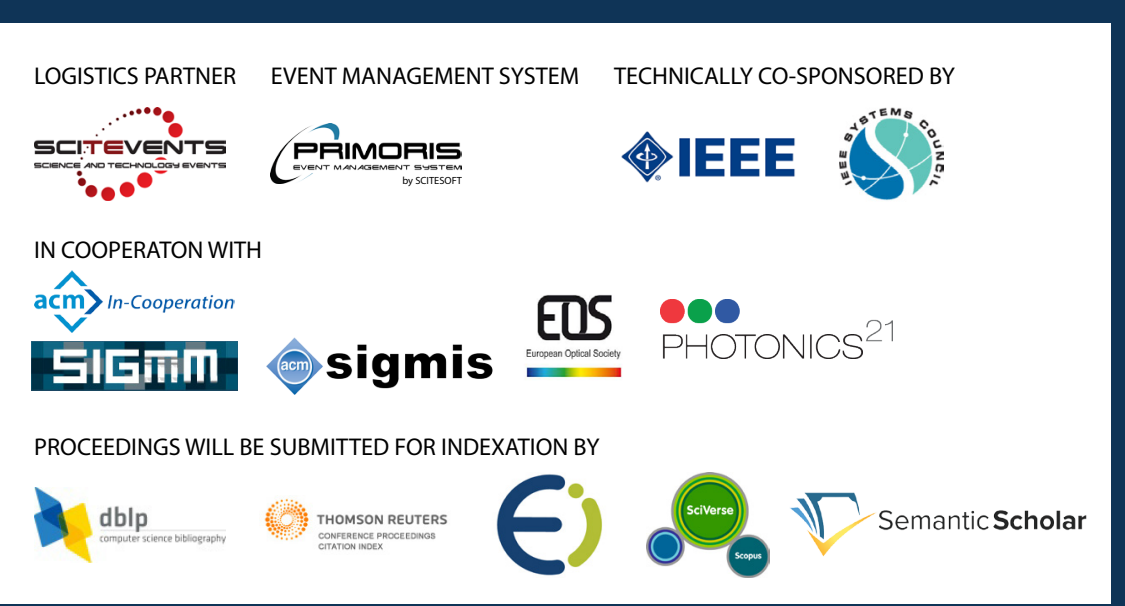

Copyright $\odot 2018$ by SCITEPRESS - Science and Technology Publications, Lda. All Rights Reserved

ISSN: $2184-2825$

ISBN: 978-989-758-319-3 